Article

\title{
Photopatternable Epoxy-Based Thermosets
}

\author{
Michael Giebler ${ }^{1}$, Simone Radl ${ }^{1}$, Thomas Ules ${ }^{1}$, Thomas Griesser ${ }^{2}$ and Sandra Schlögl ${ }^{1, *(1)}$ \\ 1 Polymer Competence Center Leoben GmbH, Roseggerstrasse 12, A-8700 Leoben, Austria \\ 2 Institute of Chemistry of Polymeric Materials, Montanuniversitaet Leoben, Otto Glöckel-Strasse 2, \\ A-8700 Leoben, Austria \\ * Correspondence: Sandra.Schloegl@pccl.at; Tel.: +43-3842-402-2354
}

Received: 5 July 2019; Accepted: 22 July 2019; Published: 24 July 2019

\begin{abstract}
The present work provides a comparative study on the photopatterning of epoxy-based thermosets as a function of network structure and network mobility. Local switching of solubility properties by light of a defined wavelength is achieved by exploiting versatile $o$-nitrobenzyl ester (o-NBE) chemistry. $o$-NBE derivatives with terminal epoxy groups are synthetized and thermally cured with different types of cycloaliphatic anhydrides via nucleophilic ring opening reaction. By varying the structure of the anhydride, glass transition temperature $\left(T_{\mathrm{g}}\right)$ and surface hardness are adjusted over a broad range. Once the network has been formed, the photolysis of the $o$-NBE groups enables a well-defined degradation of the 3D network. Fourier transform infrared (FT-IR) spectroscopy studies demonstrate that cleavage rate and cleavage yield increase with rising mobility of the network, which is either facilitated by inherent network properties ( $T_{\mathrm{g}}$ below room temperature) or a simultaneous heating of the thermosets above their $T_{\mathrm{g}}$. The formation of soluble species is evidenced by sol-gel analysis, revealing that low- $T_{g}$ networks are prone to secondary photoreactions at higher exposure doses, which lead to a re-crosslinking of the cleaved polymer chains. The change in solubility properties is exploited to inscribe positive tone micropatterns within the thermosets by photolithographic techniques. Contrast curves show that the resist performance of rigid networks is superior to flexible ones, with a contrast of 1.17 and a resolution of $8 \mu \mathrm{m}$.
\end{abstract}

Keywords: photopatterning; epoxy-based thermosets; photocleavage; o-nitrobenzyl ester; surface hardness; positive tone photoresists

\section{Introduction}

Due to their permanent network structure, classic epoxy-based thermosets are characterized by superior mechanical properties, high resistance to creep, and high thermal stability. These salient features make them ideal candidates for structural applications [1] and indispensable materials in functional coatings [2], electrical [3], and electronic devices [4]. The network formation typically relies on thermal curing routes with amines, amides, anhydrides, phenols, thiols, or imidazoles as crosslinkers [5]. The material properties of epoxy-based thermosets are governed by the structure, the curing parameters and the stoichiometric ratio both of monomer and crosslinker [6]. The curing reaction is often accelerated by the addition of selected organic molecules such as metal acetyl acetonates and tertiary amines [7].

Advancing from epoxy-based thermosets with permanent covalent crosslinks, recent research is geared towards the introduction of exchangeable chemical bonds and dynamic crosslinks, which offers a promising strategy for reshaping [8], self-healing [9,10], reprocessing [11,12], or recycling [13] of thermosets. 
Besides dynamic crosslinks, a convenient switching of network properties is realized by introducing irreversibly cleavable chromophores. Benefiting from a spatially controlled cleavage of covalent links by light exposure, the photoisomerization of $o$-NB alcohol derivatives has become a prominent strategy to impart photo-responsive properties to polymeric structures. Along with the preparation of photosensitive hydrogels [14], copolymers [15-18], or self-assembled monolayers [19], the application of $o-\mathrm{NBE}$ chemistry is of particular interest in the fabrication of patterned polymer structures and resist technology.

Various routes toward the synthesis of functional polymers for photoresists have been described, which employ $o$-NB alcohol derivatives as photocleavable binding motif. Successful approaches involved the introduction of $o$-NB ethers in the polymer backbone of poly(acrylates) and poly(ethylene glycol)s or the synthesis of poly(imide) precursors with pendant $o$-NB groups [20,21]. In addition, Ober and co-workers demonstrated the synthesis of a copolymer with perfluorinated methacrylate and o-nitrobenzyl methacrylate units, in which patterns in the sub-micrometer range were inscribed due to the ultra-violet (UV) light induced change in solubility [22]. The implementation of $o$-NB-based photoresists in organic electronics was also shown by Zojer and co-workers, who applied poly(norbornene)s with pendant $o$-NBE groups as photoreactive layers in organic thin-film transistors [23].

In the late 1980s, particular interest was also focused on the exploitation of this photocleavage reaction in chemical amplification concepts. Willson and co-workers synthetized poly(carbonate)s with $o$-nitrobenzyl pendant groups, which form free hydroxymethyl side groups upon UV exposure [24]. Chemically amplified depolymerization of the illuminated polymer was obtained during a post-baking step in the presence of a photo acid. A route towards positive chemical amplification was pursued by Wilkins et al., who described the synthesis of an o-NB ester of cholic acid [25]. The ester acted as photosensitive dissolution inhibitor for copolymers of methyl methacrylate and methyl acrylic acid. Deep UV exposure changed the solubility characteristics of the inhibitor since the cleavage products were highly soluble in alkaline solutions. In particular, positive tone patterns with a resolution of $0.5 \mu \mathrm{m}$ were accomplished.

Following the concept of an UV induced change in solubility, the application of $o$-NBE chemistry has also been expanded to patterned polymers used in biomedical applications. Doh and co-workers synthetized patternable acrylic copolymers with $o$-NBE pendant groups, which were applied in the fabrication of multicomponent protein and cell arrays [26]. Going a step beyond the fabrication of simple patterns, Li et al. realized reactive micropatterns by preparing new photodegradable polymers with $o$-NBE links in the main chain [27]. Since the $o$-NBE units were carrying additional functional groups such as epoxy, mercapto, or alkine moieties, the patterns could be modified by subsequent thiol-ene chemistry or copper catalyzed azide-alkyne cycloaddition reactions.
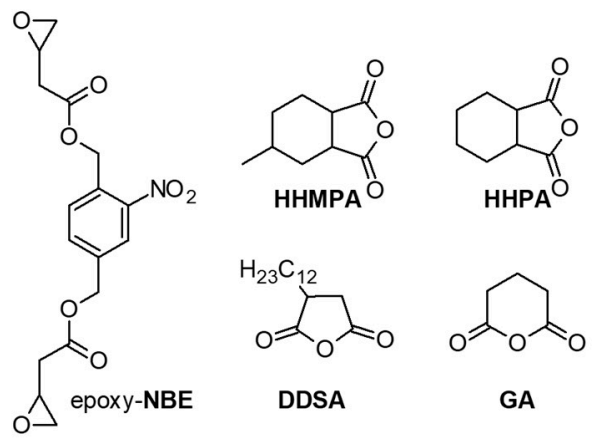

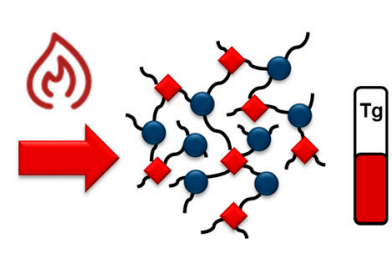

Thermal curing

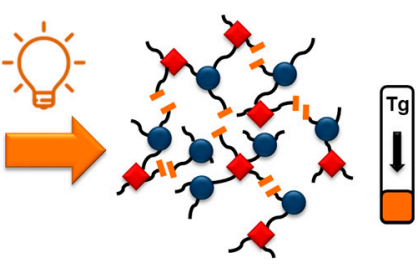

Photocleavage

Figure 1. Epoxy-NBE as photosensitive epoxy-based monomer and cycloaliphatic dicarboxylic acid anhydrides used in the preparation of photopatternable thermosets. 
Inspired by this work, we employed $o$-NBE chemistry for the fabrication of positive tone photoresists by controlled degradation of thermally cured epoxy-based networks upon UV exposure [28,29]. The photosensitive links enabled the spatially controlled degradation of the covalent polymer networks upon UV exposure and a switch both in solubility properties and thermo-mechanical performance. By using a newly synthetized $o$-NBE derivative with terminal epoxy groups, photosensitive duromer networks were prepared by a thermal curing step in the presence of an anhydride hardener. The spatial control of the network degradation was successfully exploited to prepare positive tone micropatterns.

Whilst the feasibility of the concept has already been shown in our previous work [28], the current work aims at the establishment of structure-property relationships between network composition and material properties (prior to and after photocleavage) to enhance the performance of the functional networks (Figure 1). In a comprehensive way, the anhydride hardener was varied to obtain networks with glass transition temperatures ranging between 16 and $72{ }^{\circ} \mathrm{C}$. The results revealed that the differences in network mobility significantly affect the efficiency of the cleavage reaction, the formation of soluble species, and, thus, the contrast curve of respective positive tone photoresists.

\section{Materials and Methods}

\subsection{Materials and Chemicals}

The anhydride hardeners and $N, N$ - dimethylbenzylamine as accelerator were purchased from Sigma-Aldrich (St. Louis, MO, USA) and were used without further purification. (2-Nitro-1,4phenylene) bis(methylene) bis(2-(oxiran- 2-yl)acetate) (epoxy-NBE) was synthesized as previously reported in ref. [28]. Caution: For preparative work, hazardous chemicals and solvents were employed. Reactions must be carried out in a fume hood, and protective clothes and goggles must be used.

\subsection{Preparation and Thermal Curing of Photopatternable Epoxy-Based Thermosets}

For sample preparation, epoxy-NBE was mixed with 1.0 epoxide equiv. of the respective anhydride hardener (Figure 1) and $0.1 \mathrm{wt} \%$ (related to the total reaction mixture) of $N, N$ - dimethylbenzylamine. The composition of the resin formulations is summarized in Table 1. Regarding formulations containing either dodecenylsuccinic anhydride (DDSA) or hexahydro-4-methylphthalic anhydride (HHMPA), the components were stirred in a glass vial at room temperature for $30 \mathrm{~min}$. In contrast, formulations with hexahydrophthalic anhydride (HHPA) or glutaric anhydride (GA) were heated to $50{ }^{\circ} \mathrm{C}$ in a water bath (to dissolve the anhydride in epoxy-NBE) and stirred for $30 \mathrm{~min}$. Thermal curing of all formulations was carried out at $100^{\circ} \mathrm{C}$ for $18 \mathrm{~h}$ yielding solid samples.

Table 1. Composition of photopatternable epoxy-based resin formulations.

\begin{tabular}{cccc}
\hline Resin Formulation & Type of Anhydride & Molar Ratio ${ }^{\mathbf{1}}$ & Accelerator [wt $\%$ ] \\
\hline epoxy-NBE/HHMPA & HHMPA & 1 & 0.1 \\
epoxy-NBE/HHPA & HHPA & 1 & 0.1 \\
epoxy-NBE/DDSA & DDSA & 1 & 0.1 \\
epoxy-NBE/GA & GA & 1 & 0.1 \\
\hline
\end{tabular}

${ }^{1}$ Molar ratio of anhydride crosslinker to epoxy-NBE in resin formulation.

\subsection{Characterization of Curing and Cleavage Kinetics}

To monitor the progress of the thermally induced ring-opening reaction between epoxy-NBE and the anhydride hardener, as well as the subsequent photo-induced cleavage of the $o$-NBE links, FT-IR spectroscopy with a Vertex 70 spectrometer (Bruker, Billerica, United States) was carried out. Sixteen scans were accumulated in transmission mode with a resolution of $4 \mathrm{~cm}^{-1}$. The areas of the IR absorption peaks were calculated with OPUS software (Version 7.0, Bruker, Billerica, MA, USA). For sample preparation, the resin formulations were drop-cast between a $\mathrm{Si}$ wafer and a $\mathrm{CaF}_{2}$ substrate 
and cured at $100^{\circ} \mathrm{C}$. The curing kinetics was monitored for $18 \mathrm{~h}$ and Fourier transform infrared (FT-IR) spectra were recorded at predefined times.

Regarding the cleavage kinetics, the drop-cast films of the cured material were irradiated with a medium pressure Hg lamp (Omnicure S1000, Lumen Dynamics, ON, Canada) under nitrogen atmosphere. The cleavage reaction was followed upon prolonged UV exposure. To determine the light intensity (power density $\mathrm{P}$; in $\mathrm{mW} \mathrm{cm}^{-2}$ ) on the sample plane an integrated radiometer (Powerpuck II, EIT Instrument Markets, Leesburg, VA, USA) was used. The average power density was $114.4 \mathrm{~mW} \mathrm{~cm} \mathrm{~cm}^{-2}$ (between 250 and $470 \mathrm{~nm}$ ).

\subsection{Characterization of Network Properties}

The glass transition temperature $\left(T_{\mathrm{g}}\right)$ of cured samples was determined prior to and after UV exposure by differential scanning calorimetry (DSC) using a Mettler-Toledo DSC 821e (Columbus, $\mathrm{OH}, \mathrm{USA}$ ). For the analysis, the cured resins were heated from -20 to $120{ }^{\circ} \mathrm{C}$ with a heating rate of $20^{\circ} \mathrm{C} \mathrm{min}{ }^{-1}$. The resulting $T_{\mathrm{g}}$ was characterized from the first heating run and was read as the midpoint in heat capacity. Regarding the sample preparation, $7-10 \mathrm{mg}$ of the uncured resin formulation was placed into an aluminum crucible (Mettler-Toledo, $40 \mu \mathrm{L}$, Columbus, OH, USA) and cured for $18 \mathrm{~h}$ at $100^{\circ} \mathrm{C}$. Subsequent UV exposure was carried out as described in the previous section.

Nanoindentation experiments were performed to determine the surface hardness with the Ultra Nanoindentation Tester (Anton Paar, Graz, Austria) using a pyramidal-shaped Berkovich tip with an equivalent cone semi-angle $q=70.3^{\circ}$. The contact force was $50 \mu \mathrm{N}$, and the maximum indentation force was set to $1000 \mu \mathrm{N}$. Both loading and unloading rate amounted to $6000 \mu \mathrm{N} / \mathrm{min}$. A $30 \mathrm{~s}$ hold segment was applied at the maximum load to obtain reliable stress-strain curves. $H_{\mathrm{IT}}$ data were derived from the unloading-part of the load-displacement curve according to the "Oliver \& Pharr Method" [30]. In this method, the indentation hardness $\left(H_{\mathrm{IT}}\right)$ as a measure for surface hardness is equivalent to the mean pressure supported by the sample under maximum load. The distance between two measuring points was $150 \mu \mathrm{m}$, and nine indents were performed in total over an area of $300 \times 300 \mu \mathrm{m}$ to record the mechanical properties over a larger length scale and to get reliable results.

\subsection{Preparation and Characterization of Photopatterned Films}

For sol-gel analysis, thin films were obtained by drop-casting the resin formulations between a Si waver and a polypropylene foil. After curing at $100^{\circ} \mathrm{C}$ for $18 \mathrm{~h}$, the polymer foil was removed, and the cured film was irradiated with a medium Hg lamp (Omnicure S1000, Lumen Dynamics, ON, Canada) under nitrogen for defined periods of time. To study the change of the gel fraction, FT-IR spectra (Vertex 70 spectrometer, Bruker, Billerica, MA, USA) of the non-exposed and UV exposed samples were taken after development in tetrahydrofuran for $10 \mathrm{~min}$. Contrast curves were obtained by plotting the gel fractions versus the log function of the exposure dose.

Micropatterns were inscribed in the cured resin formulations by photolithography. Cured thin films were prepared as described in the previous paragraph. Photolithographic patterning was then performed with a quartz-chromium mask in contact mode with the Omnicure S1000 (Lumen Dynamics, ON, Canada) as light source. The exposure dose amounted to $22.3 \mathrm{~J} / \mathrm{cm}^{2}$ for cured epoxy-NBE/HHMPA, epoxy-NBE/HHPA and epoxy-NBE/DDSA systems. In terms of epoxy-NBE/GA networks an exposure dose of $8.5 \mathrm{~J} / \mathrm{cm}^{2}$ was applied. The polymer films were developed by dipping the samples for few seconds in tetrahydrofuran.

Surface topography measurements were conducted with the 3D optical surface metrology system Leica DCM8 (Leica Microsystems, Wetzlar, Germany). The images were obtained using a Mirau 20x objective and the ePSI (extended Phase Shift Interferometry) mode, with blue light. This allows for a theoretical optical resolution of $0.35 \mu \mathrm{m}$ and a vertical resolution better than $1 \mathrm{~nm}$. 


\section{Results and Discussion}

\subsection{Thermal Curing of Photopatternable Epoxy-Based Thermosets}

Photopatternable thermosets were prepared by thermal curing of the epoxy-terminated $o$-NBE derivative (epoxy-NBE) with selected cycloaliphatic anhydrides (Figure 2a). Moreover, a tertiary amine was added as an accelerator to reduce both time and temperature of the cure reaction. The mechanism of the accelerated curing follows a ring opening reaction of the anhydride by the amine under the formation of betaines [6]. The internal salts provide carboxylate ions, which initiate the cure reaction by forming alkoxide esters with the epoxy groups. Once formed, the alkoxide esters react with further anhydride groups yielding carboxylate anion functional esters. Those are able to open epoxy moieties leading to a perpetuation of the ring-opening reaction.
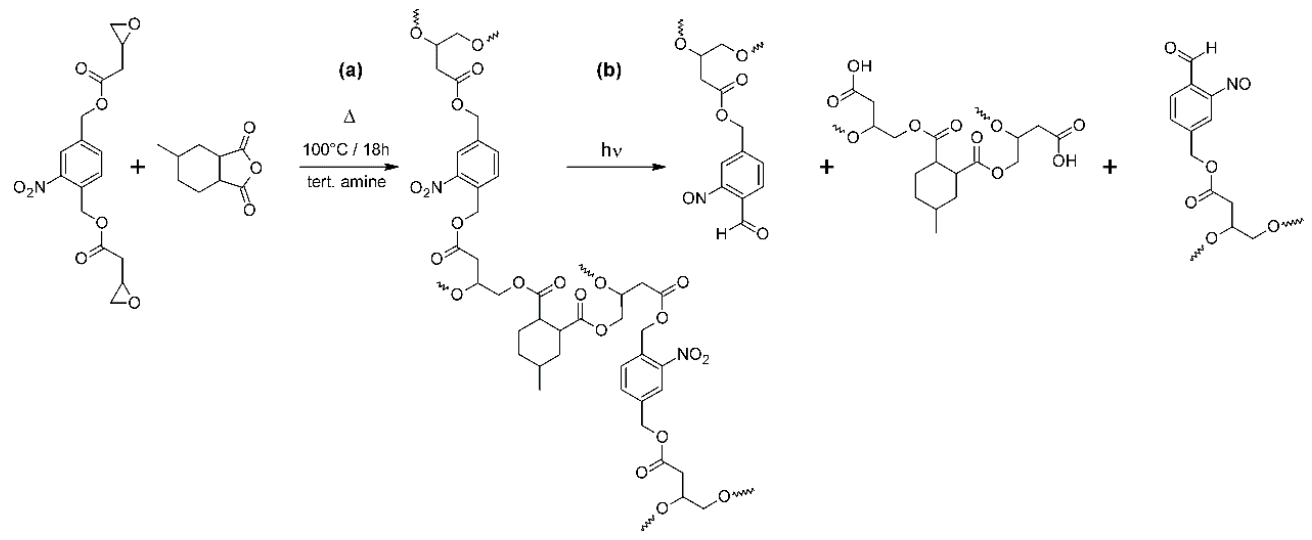

Figure 2. (a) Thermal curing and (b) photocleavage of epoxy-based thermosets with photosensitive $o$-NBE links.

For determination of the cure kinetics, the resin formulations were drop-cast between a $\mathrm{CaF}_{2}$ disc and a Si wafer. Figure 3a displays the FT-IR spectra of epoxy-NBE/HHPA prior to and after thermal curing at $100{ }^{\circ} \mathrm{C}$. In the cured state, the two carbonyl peaks (1860 and $1778 \mathrm{~cm}^{-1}$ ) related to the anhydride group disappeared whilst a new band arose at $1740 \mathrm{~cm}^{-1}$, which can be assigned to the carbonyl unit of the formed ester linkages. In addition, the epoxy peak at $910 \mathrm{~cm}^{-1}$ disappeared confirming the successful network formation by the nucleophilic ring-opening reaction. Identical observations were made for the other epoxy/anhydride formulations under investigation (Figure S1a-c in Supplementary Materials).

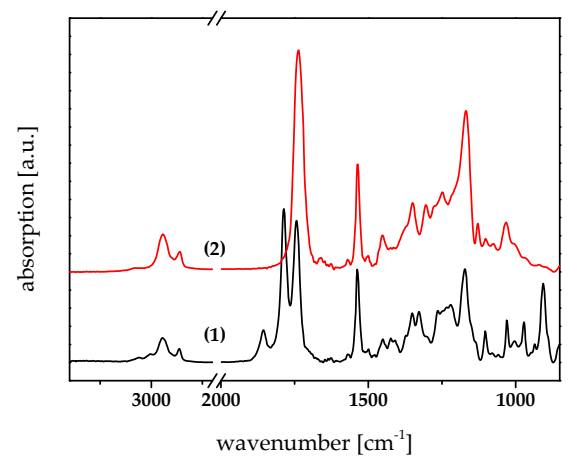

(a)

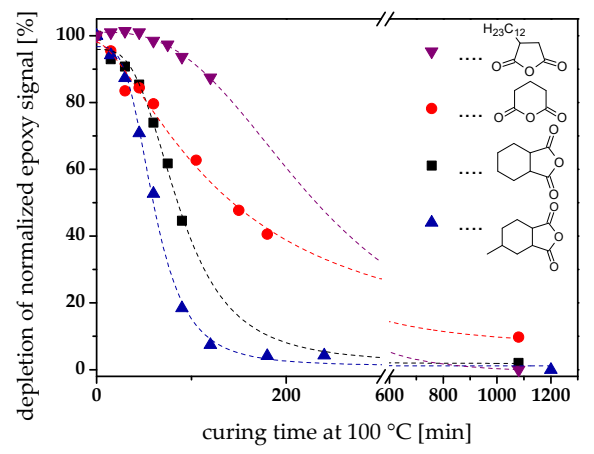

(b)

Figure 3. (a) Fourier transform infrared (FT-IR) spectra of epoxy-NBE/HHPA (1) prior to and (2) after thermal curing at $100^{\circ} \mathrm{C}$. (b) Influence of the anhydride structure on the cure kinetics of photopatternable epoxy-based thermosets by following the normalized depletion of the peak area between 910 and $928 \mathrm{~cm}^{-1}$. Thermal curing was performed at $100{ }^{\circ} \mathrm{C}$. The lines are a guide for the eye. 
To study the influence of the anhydride structure on the cure kinetics, the depletion of the epoxy peak at $910 \mathrm{~cm}^{-1}$ was followed upon curing at $100{ }^{\circ} \mathrm{C}$ (Figure 3b). Since this epoxy band partly overlaps with an absorption band of the anhydride group at $920 \mathrm{~cm}^{-1}$, the depletion of both signals was monitored. The results reveal that the curing rate decreases in the order of HHMPA $>$ HHPA $>$ GA $>$ DDSA. Whilst for MHHPA nearly full conversion was observed after a curing time of $180 \mathrm{~min}$, prolonged curing (> $1000 \mathrm{~min}$ ) is required, both for GA and DDSA, to reach a conversion above $90 \%$. The long alky chain in its structure may explain the low reactivity of DDSA. On the one hand, it lowers the acidity of the anhydride groups and on the other hand, it might hamper the reaction due to steric effects. A comparable behavior was found for nonyl succinic anhydride in the non-catalyzed ring-opening of epoxy resins [31].

In contrast, the lower reactivity of GA compared to HHMPA or HHPA might be related to the higher stability (lower ring strain) of the six-membered ring system. Previous studies on the ring-opening copolymerization of epoxides and anhydrides showed that a decrease of the ring strain (of either epoxides or anhydrides) corresponds to a lower reactivity of the monomers and results in lower molecular weight products [32,33].

Along with cure kinetics, the structure of the anhydride affects thermo-mechanical properties and surface hardness, as shown in Table 2. From DSC measurements, it is obtained, that more rigid anhydrides (HHMPA and HHPA) yield networks with glass transition temperatures $\left(T_{\mathrm{g}}\right)$ of 72 and $46{ }^{\circ} \mathrm{C}$, respectively. In contrast, epoxy-NBE/GA networks comprise a $T_{\mathrm{g}}$ below room temperature, which is attributed to the flexible nature of the anhydride in its opened state. In contrast, curing with DDSA gives networks with a $T_{\mathrm{g}}$, which is only slightly lower $\left(44^{\circ} \mathrm{C}\right)$ than the epoxy-NBE/HHPA system. DDSA cured epoxy thermosets with a $T_{\mathrm{g}}$ in the range of $40^{\circ} \mathrm{C}$ were also reported by Webster and Pan, who established structure-property relationships of epoxy-based resins from renewable resources [34].

The indentation hardness $\left(H_{\mathrm{IT}}\right)$ of the cured resins under investigation correlates well with the respective $T_{\mathrm{g}}$ values and increases in the order of GA $>$ DDSA $>$ HHPA $>$ HHMPA. Depending on the structure of the anhydride, the surface hardness varied over three orders of magnitude: from the soft epoxy-NBE/GA system with a surface hardness of $8.6 \pm 0.8 \mathrm{MPa}$ to the rigid epoxy-NBE/HHMPA network with $213.5 \pm 19.8 \mathrm{MPa}$.

Table 2. Glass transition temperature $\left(T_{\mathrm{g}}\right)$ and indentation hardness $\left(H_{\mathrm{IT}}\right)$ of cured photopatternable epoxy-based thermosets prior to and after UV exposure $\left(74.5 \mathrm{~mW} \mathrm{~cm}^{-2}\right)$.

\begin{tabular}{lcccc}
\hline \multirow{2}{*}{ Resin Formulation } & $\boldsymbol{T}_{\mathbf{g}}\left[{ }^{\circ} \mathbf{C}\right]$ & $\boldsymbol{H}_{\mathrm{IT}}[\mathrm{MPa}]$ & $\boldsymbol{T}_{\mathbf{g}}\left[{ }^{\circ} \mathrm{C}\right]$ & $\boldsymbol{H}_{\mathrm{IT}}[\mathrm{MPa}]$ \\
\cline { 2 - 5 } & \multicolumn{2}{c}{ Thermally Cured } & \multicolumn{2}{c}{ Photocleaved } \\
\hline epoxy-NBE/HHMPA & 72 & $213.5 \pm 19.8$ & 48 & $110.9 \pm 10.3$ \\
epoxy-NBE/HHPA & 46 & $148.6 \pm 13.8$ & 32 & $83.0 \pm 6.3$ \\
epoxy-NBE/DDSA & 44 & $51.0 \pm 4.7$ & 30 & $41.3 \pm 3.8$ \\
epoxy-NBE/GA & 16 & $8.6 \pm 0.8$ & 12 & $1.3 \pm 0.1$ \\
\hline
\end{tabular}

\subsection{Photocleavage of Photopatternable Epoxy-Based Thermosets}

The photocleavage of the epoxy-based networks was subsequently monitored in cured films, which were drop-cast between $\mathrm{a} \mathrm{CaF}_{2}$ disc and a $\mathrm{Si}$ wafer. The samples were irradiated with UV-light at wavelengths below $400 \mathrm{~nm}$ to induce the cleavage reaction of the $o-\mathrm{NBE}$ links. The ester photolysis typically yields nitroso compounds and carboxylic acids as primary cleavage products (Figure 2b) [35]. In the present study, the cleavage is evidenced by the depletion of the two characteristic $\mathrm{NO}_{2}$ signals at $1537 \mathrm{~cm}^{-1}$ and $1348 \mathrm{~cm}^{-1}$ (conversion of nitro groups to nitroso moieties). The related spectra are provided in Figure S2a-d in Supplementary Materials. In addition, a distinctive broadening of the $\mathrm{C}=\mathrm{O}$ absorption band $\left(1646-1830 \mathrm{~cm}^{-1}\right)$ is observed, which is associated with the formation of carboxylic acids and other carbonyl-based cleavage products. 
The cleavage kinetics was determined as a function of the employed anhydride by following the depletion of the $\mathrm{NO}_{2}$ signal at $1537 \mathrm{~cm}^{-1}$ upon prolonged UV irradiation (Figure 4a). A rapid decrease of the nitro absorption band was observed in the low- $\mathrm{T}_{\mathrm{g}}$ network epoxy-NBE/GA. This is in good agreement with previous studies, in which we have reported that the photocleavage kinetics of $o$-NBE links is influenced by the mobility of the chromophore [36]. However, it is interesting to note that epoxy-NBE/HHPA and epoxy-NBE/DDSA networks, whose $T_{\mathrm{g}}$ is above room temperature (46 and $44{ }^{\circ} \mathrm{C}$, respectively), comprise a cleavage rate that is equal to the epoxy-NBE/GA system. This might be explained by the temperature of the sample's surface, which rises to $38-40{ }^{\circ} \mathrm{C}$ during UV exposure. Consequently, the UV exposure is carried out either above or close to the $T_{\mathrm{g}}$, which ensures a high mobility of the networks resulting in comparable cleavage kinetics.

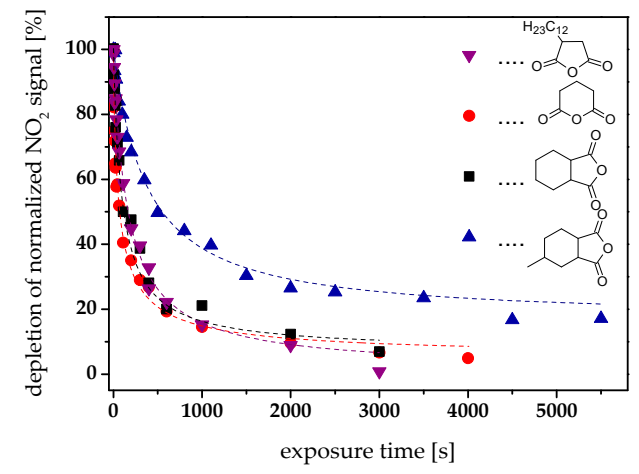

(a)

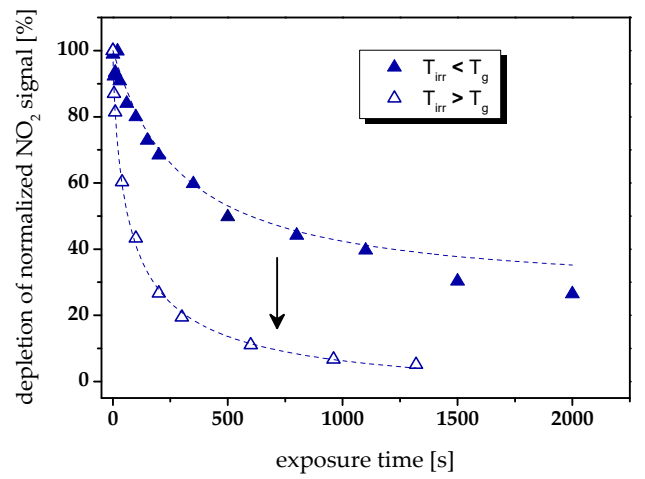

(b)

Figure 4. (a) Cleavage kinetics of photopatternable epoxy-based thermosets versus anhydride structure. The normalized depletion of the nitro groups (at $1537 \mathrm{~cm}^{-1}$ ) is followed upon prolonged UV irradiation $\left(74.5 \mathrm{~mW} \mathrm{~cm}^{-2}\right)$. The lines are a guide for the eye. (b) Normalized depletion of the nitro groups (at $1537 \mathrm{~cm}^{-1}$ ) in epoxy-NBE/HHMPA networks as a function of the reaction temperature: (full triangles) no additional heating of the sample during UV exposure $\left(T_{\mathrm{irr}}<T_{\mathrm{g}}\right)$ and (open triangles) simultaneous heating of the sample to $80{ }^{\circ} \mathrm{C}\left(T_{\text {irr }}>T_{\mathrm{g}}\right)$. The lines are a guide for the eye.

In contrast, the high- $\mathrm{T}_{\mathrm{g}}$ network $\left(72^{\circ} \mathrm{C}\right)$ epoxy-NBE/HHMPA is characterized by a significantly lower cleavage rate due to the lower mobility of the chromophore under irradiation conditions. This can be easily overcome by simultaneously heating the sample to $80^{\circ} \mathrm{C}\left(T_{\mathrm{irr}}>T_{\mathrm{g}}\right)$ during UV exposure. As shown in Figure $4 \mathrm{~b}$, the higher temperature significantly accelerates the cleavage rate and leads to a higher conversion of the nitro groups, confirming the important role of network mobility on the cleavage kinetics of $o$-NBE based networks.

The photo-induced degradation of the networks is reflected by the decrease of the $T_{\mathrm{g}}$ as well as the surface hardness (Table 2). The optically triggered change in material properties is more pronounced in networks containing rigid anhydrides such as HHMPA or HHPA. In particular, for epoxy-NBE/HHMPA systems, the $T_{\mathrm{g}}$ decreases from 72 to $48{ }^{\circ} \mathrm{C}$, whilst in terms of epoxy-NBE/GA networks, the change in the $T_{\mathrm{g}}$ does not exceed $4{ }^{\circ} \mathrm{C}$. With respect to the surface hardness, a similar trend was observed.

In further experiments, the influence of simultaneous heating was studied by measuring the surface hardness of the high- $\mathrm{T}_{\mathrm{g}}$ network epoxy-NBE/HHMPA as a function of the reaction temperature. Without additional heating, the surface hardness is nearly halved by the UV-induced network degradation and the $H_{\mathrm{IT}}$ value decreases from $213.5 \pm 19.8$ to $110.9 \pm 10.3 \mathrm{MPa}$. By simultaneously heating the sample to either 50 or $70^{\circ} \mathrm{C}$, the $H_{\mathrm{IT}}$ values further decreased to $40.6 \pm 3.8$ and $29.1 \pm 2.7 \mathrm{MPa}$, respectively. From the results, it can be concluded that the cleavage of $o$-NBE linkages facilitates network degradation, whose efficiency can be significantly increased by rising reaction temperature and, thus, mobility of the thermosets. 


\subsection{Photopatterning Studies}

For a successful positive tone patterning of the epoxy-based networks under investigation, the photo-induced formation of soluble species is crucial. Thus, sol-gel analysis was performed on thin cured resins, which were UV irradiated for selected exposure doses and developed in tetrahydrofuran. The insoluble fraction was then determined by quantitative FT-IR spectroscopy. Figure 4a-d show the gel fraction of the four thermosets versus exposure time.

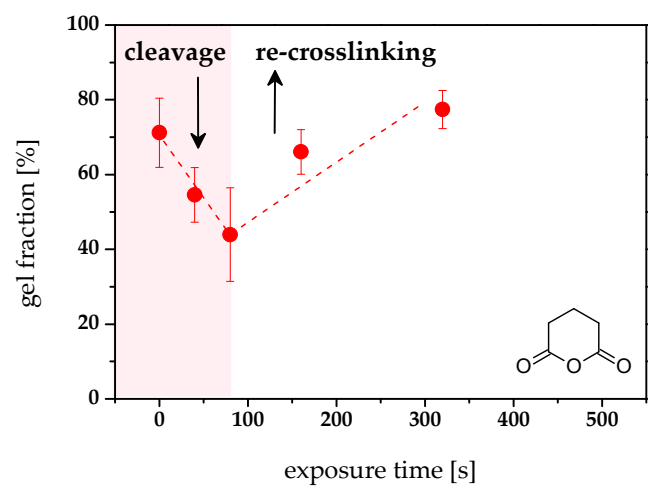

(a)

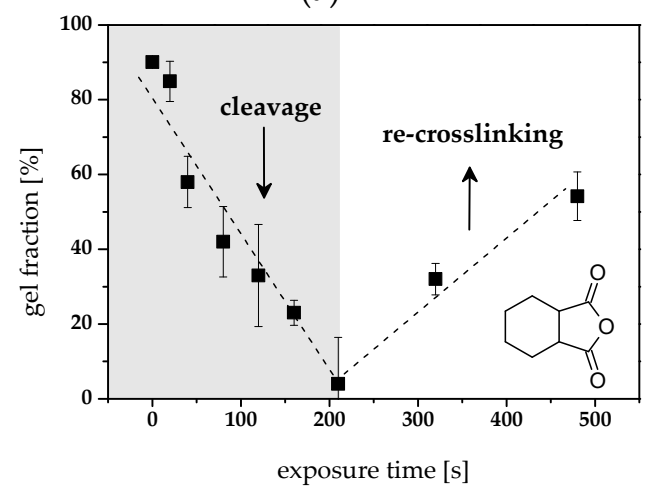

(c)

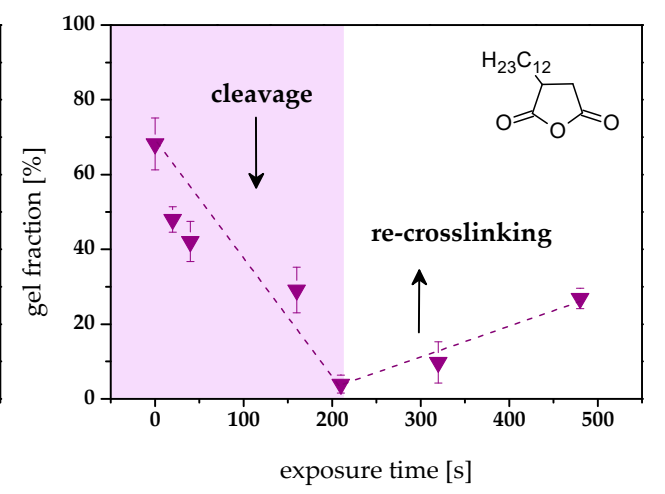

(b)

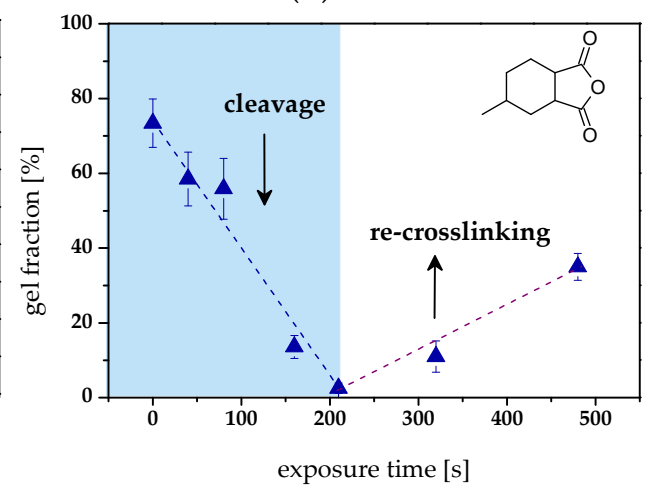

(d)

Figure 5. Gel fraction of (a) epoxy-NBE/GA, (b) epoxy-NBE/DDSA, (c) epoxy-NBE/HHPA and (d) epoxy$\mathrm{NBE} / \mathrm{HHMPA}$ versus exposure time $\left(75 \mathrm{~mW} / \mathrm{cm}^{2}\right)$ as derived from quantitative FT-IR measurements.

Whilst epoxy-NBE/GA, epoxy-NBE/DDSA, and epoxy-NBE/HHPA networks were characterized by comparable cleavage rates and cleavage yields (Figure 3a), their ability to form soluble cleavage products differs significantly. For the low- $\mathrm{T}_{\mathrm{g}}$ network epoxy-NBE/GA, a gradual decrease of the gel fraction is observed with rising UV irradiation until a minimum of $42 \%$ is reached (Figure $5 \mathrm{a}$ ). A further increase in the exposure time leads to an increase in the gel fraction, which is explained by a reformation of covalent links. Previous work showed that secondary cleavage products are readily formed in highly mobile polymer networks (e.g., formation of azobenzene moieties) leading to a re-crosslinking of the networks $[29,36]$. In contrast, the epoxy-NBE/DDSA network with a $T_{\mathrm{g}}$ above room temperature becomes fully soluble at an exposure time of $200 \mathrm{~s}$ (Figure 5b). At prolonged UV exposure (> $200 \mathrm{~s}$ ), a re-crosslinking of the cleaved polymer chains was again observed. Networks with rigid anhydrides showed the same behavior (Figure $5 \mathrm{c}, \mathrm{d}$ ). The results confirm that mobile $o$-NBE networks are more prone to side reactions compared to rigid ones. This correlates well with the UV-induced changes in surface hardness and $T_{\mathrm{g}}$, which are less pronounced in flexible networks. Similar behavior was also observed in recent studies on photocleavable thiol-ene, thiol-yne, and polydimethyl siloxane networks, which have a $T_{\mathrm{g}}$ below room temperature and are highly susceptible to re-crosslinking due to secondary photoreactions [36-39]. 


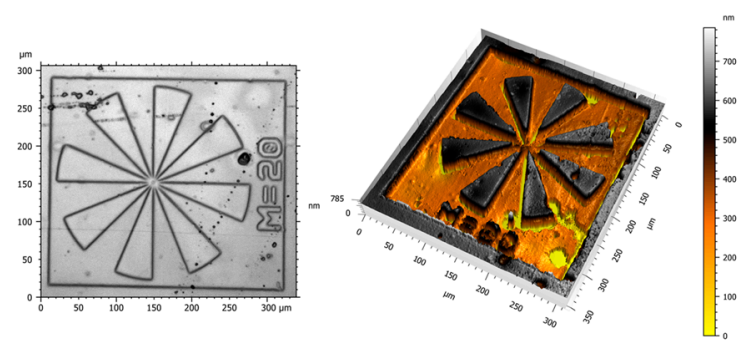

(a)

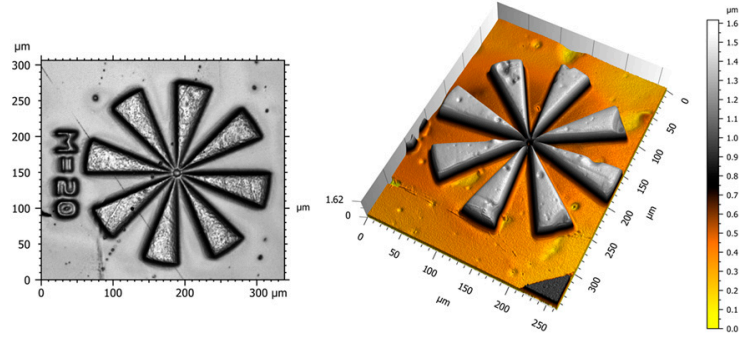

(c)
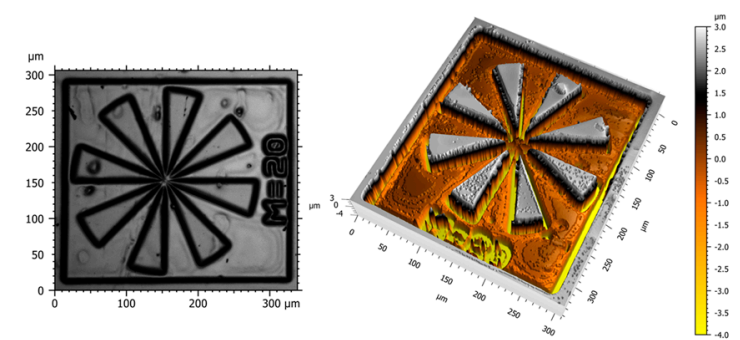

(b)
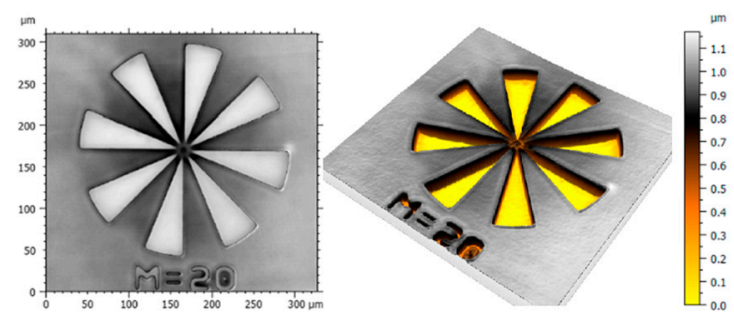

(d)

Figure 6. Micrographs and surface profiles of photopatterned (a) epoxy-NBE/GA, (b) epoxy-NBE/DDSA, (c) epoxy-NBE/HHPA, and (d) epoxy-NBE/HHMPA systems as obtained from interference microscopy.

Table 3. Characteristics of positive tone photoresists based on photocleavable epoxy-based thermosets.

\begin{tabular}{lcccc}
\hline Resin Formulation & $\boldsymbol{D}_{\mathbf{0}}\left[\mathbf{J} / \mathbf{c m}^{\mathbf{2}}\right]$ & $\boldsymbol{D}_{\mathbf{1 0 0}}\left[\mathbf{J} / \mathbf{c m}^{\mathbf{2}}\right]$ & $\gamma$ & Resolution $[\boldsymbol{\mu m}]$ \\
\hline epoxy-NBE/HHMPA & 16.3 & 2.27 & 1.17 & 8 \\
epoxy-NBE/HHPA & 19.5 & 0.26 & 0.53 & $>10$ \\
epoxy-NBE/DDSA & 19.7 & 0.25 & 0.53 & $>10$ \\
\hline
\end{tabular}

Although epoxy-NBE/GA systems suffer from incomplete network degradation, the formation of soluble products is reasonably efficient for inscribing positive tone relief structures in the thermosets by photolithography (Figure 6a). For the other three resin systems, which are becoming fully soluble upon UV exposure, characteristic photoresist properties, such as contrast and resolution, were determined (Table 3). The contrast is a measure of the solubility change of the resist upon UV exposure, and contrast curves were determined by plotting the gel fraction (which corresponds to the thickness of the resist layer after the development step) as a log function of exposure dose (Figure 7a,b). The contrast $(\gamma)$ was calculated according to the following equation:

$$
\gamma=\frac{1}{\log \left(\frac{D_{0}}{D_{100}}\right)},
$$

in which $D_{0}$ and $D_{100}$ correspond to the exposure dose obtained by taking the slope of the linear portion of the contrast curve and extrapolating it to a gel content of $0 \%$ and $100 \%$, respectively [40]. From the contrast curves, it can be obtained that the exposure dose at which complete solubility is reached $\left(D_{100}\right)$ is in a similar range for all three networks under investigation. However, the $D_{0}$ value of epoxy-NBE/HHMPA systems was significantly lower than in epoxy-NBE/DDSA and epoxy-NBE/HHPA networks, which resulted in a higher contrast (1.17 versus 0.53$)$.

Topography images of the positive tone patterns inscribed in epoxy-NBE/DDSA, epoxy-NBE/HHPA and epoxy-NBE/HHMPA systems are shown in Figure $6 \mathrm{~b}-\mathrm{d}$. Whilst the exposed areas facilitated a rapid development, no significant swelling was observed in the crosslinked areas, which have not been illuminated. 
In a subsequent step, the resolution was determined by pursuing a classical approach with patterns comprising lines and spaces with varying widths and by investigating the polymer patterns after the development. For epoxy-NBE/HHMPA networks, separate lines and spaces of the positive tone patterns were observed until a pattern width of $8 \mu \mathrm{m}$ was reached. In contrast, epoxy-NBE/HHPA and epoxy-NBE/DDSA networks are characterized by a lower resolution $(>10 \mu \mathrm{m})$. This correlates well with the lower contrast observed in these two thermosets. It should be further noted that the contrast is lower compared to resists used in the microelectronic industry, which typically have a contrast in the range of 2-3 [40]. However, the photo-induced conversion of an insoluble thermoset to soluble cleavage products paves the way toward a versatile and convenient micropatterning of epoxy-based duromers.

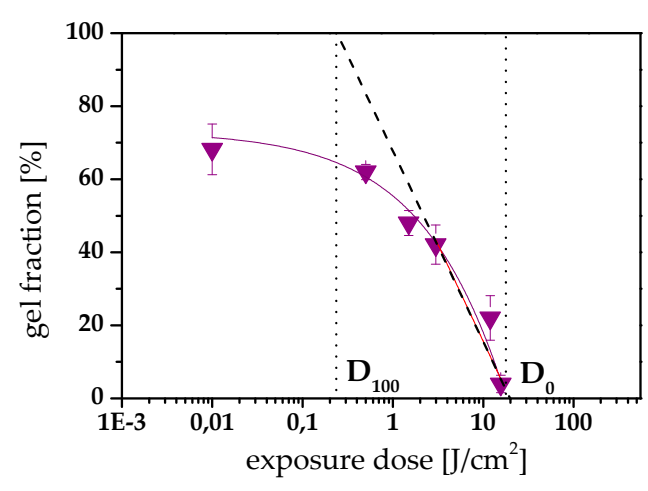

(a)

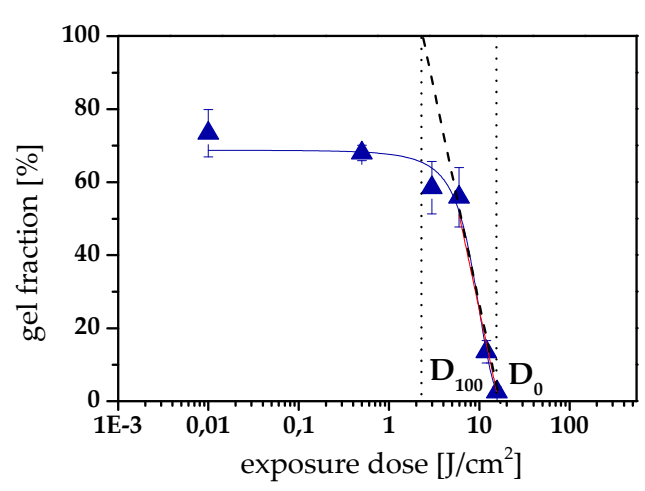

(b)

Figure 7. Contrast curves of (a) epoxy-NBE/DDSA and (b) epoxy-NBE/HHMPA networks and calculation of the contrast $(\gamma)$ from the slope of the linear area (dashed line) of the curve by extrapolating it to a gel content of $0 \%\left(D_{0}\right)$ and $100 \%\left(D_{100}\right)$, respectively.

\section{Conclusions}

Structure-property relationships of photopatternable epoxy-based thermosets were established clearly, showing the important role of network structure and network mobility on the cleavage kinetics, material properties, and related patterning performance of the photosensitive networks. Network mobility of the thermosets was conveniently adjusted by either varying the anhydride hardener or by increasing the reaction temperature during UV irradiation. Along with cure kinetics, the anhydride hardener affects material properties such as $T_{\mathrm{g}}$ and surface hardness. In particular, low- $T_{\mathrm{g}}$ networks (epoxy-NBE/GA) with a $T_{g}$ of $16{ }^{\circ} \mathrm{C}$ as well as high- $T_{g}$ networks (epoxy-NBE/HHMPA) with a $T_{g}$ of $72{ }^{\circ} \mathrm{C}$ were obtained. The network mobility strongly influences the photolysis of the $o$-NBE linkages. High- $\mathrm{T}_{\mathrm{g}}$ networks are characterized by a lower cleavage rate, which can be easily overcome by heating the networks above their $T_{\mathrm{g}}$ during UV irradiation. However, sol-gel analysis reveals that flexible networks are prone to secondary photoreactions. The side reactions lead to a re-crosslinking of the network and an incomplete formation of soluble species. In contrast, networks with a $T_{\mathrm{g}}$ above room temperature become fully soluble due to the photolysis of the $o$-NBE chromophores. Thus, although high- $\mathrm{T}_{\mathrm{g}}$ networks suffer from lower cleavage rates, they benefit from a better patterning performance. In particular, epoxy-NBE/HHMPA systems facilitate a resolution of $8 \mu \mathrm{m}$ and a contrast of 1.17 without any optimization.

Supplementary Materials: The following are available online at http://www.mdpi.com/1996-1944/12/15/2350/s1, Figure S1: FT-IR spectra of (a) epoxy-NBE/GA, (b) epoxy-NBE/DDSA, and (c) epoxy-NBE/HHMPA prior to and after thermal curing at $100{ }^{\circ} \mathrm{C}$, Figure S2: FT-IR spectra of (a) epoxy-NBE/GA, (b) epoxy-NBE/DDSA, and (c) epoxy-NBE/HHMPA prior to and after photocleavage.

Author Contributions: All authors have contributed to the preparation of this manuscript. Conceptualization, S.S.; Data curation, M.G. and T.U.; Investigation, M.G. and T.U.; Methodology, S.R. and S.S.; Supervision, S.S.; Writing—original draft, S.S.; Writing—review \& editing, T.G. 
Funding: This research work was performed at the Polymer Competence Center Leoben GmbH (PCCL, Austria) within the framework of the COMET-program of the Federal Ministry for Transport, Innovation and Technology and Federal Ministry for Economy, Family and Youth with contributions by the Institute of Chemistry of Polymeric Materials (Montanuniversitaet Leoben, Austria). The PCCL is funded by the Austrian Government and the State Governments of Styria, Upper and Lower Austria (grant number: 854178). The research was further supported by the project RETINA which is being implemented and co-financed from the European Union-European Regional Development Fund in the frame of the Cooperation Programme Interreg V-A Slovenia-Austria in the programme period 2014-2020.

Acknowledgments: The authors thank Markus Ast and Viktoria Wieser for their dedicated help during the preparation of the samples.

Conflicts of Interest: The authors declare no conflict of interest.

\section{References}

1. Ratna, D. Handbook of Thermoset Resins, 1st ed.; iSmithers: Shropshire, UK, 2009; ISBN 978-1-84735-410-5.

2. Sangermano, M.; Pegel, S.; Pötschke, P.; Voit, B. Antistatic Epoxy Coatings with Carbon Nanotubes Obtained by Cationic Photopolymerization. Macromol. Rapid Commun. 2008, 29, 396-400. [CrossRef]

3. Pleşa, I.; Noţingher, P.; Stancu, C.; Wiesbrock, F.; Schlögl, S. Polyethylene Nanocomposites for Power Cable Insulations. Polymers 2019, 11, 24. [CrossRef] [PubMed]

4. Johnston, K.; Pavuluri, S.K.; Leonard, M.T.; Desmulliez, M.P.Y.; Arrighi, V. Microwave and thermal curing of an epoxy resin for microelectronic applications. Thermochim. Acta 2015, 616, 100-109. [CrossRef]

5. Vidil, T.; Tournilhac, F.; Musso, S.; Robisson, A.; Leibler, L. Control of reactions and network structures of epoxy thermosets. Prog. Polym. Sci. 2016, 62, 126-179. [CrossRef]

6. Ellis, B. Chemistry and Technology of Epoxy Resins; Springer: Berlin/Heidelberg, Germany, 1993.

7. Pleşa, I.; Noţingher, P.; Schlögl, S.; Sumereder, C.; Muhr, M. Properties of Polymer Composites Used in High-Voltage Applications. Polymers 2016, 8, 173. [CrossRef] [PubMed]

8. Wang, Z.; Li, Z.; Wei, Y.; Ji, Y. Gold Nanospheres Dispersed Light Responsive Epoxy Vitrimers. Polymers 2018, 10, 65. [CrossRef]

9. Yang, Y.; Terentjev, E.M.; Wei, Y.; Ji, Y. Solvent-assisted programming of flat polymer sheets into reconfigurable and self-healing 3D structures. Nat. Commun. 2018, 9, 1906. [CrossRef] [PubMed]

10. Radl, S.; Kreimer, M.; Griesser, T.; Oesterreicher, A.; Moser, A.; Kern, W.; Schlögl, S. New strategies towards reversible and mendable epoxy based materials employing [4 $4 \mathrm{~s}+4 \pi \mathrm{s}]$ photocycloaddition and thermal cycloreversion of pendant anthracene groups. Polymer 2015, 80, 76-87. [CrossRef]

11. Brutman, J.P.; Delgado, P.A.; Hillmyer, M.A. Polylactide Vitrimers. ACS Macro Lett. 2014, 3, 607-610. [CrossRef]

12. Fortman, D.J.; Brutman, J.P.; Cramer, C.J.; Hillmyer, M.A.; Dichtel, W.R. Mechanically activated, catalyst-free polyhydroxyurethane vitrimers. J. Am. Chem. Soc. 2015, 137, 14019-14022. [CrossRef]

13. Imbernon, L.; Norvez, S. From landfilling to vitrimer chemistry in rubber life cycle. Eur. Polym. J. 2016, 82, 347-376. [CrossRef]

14. Bertrand, O.; Gohy, J.F. Photo-responsive polymers: Synthesis and applications. Polym. Chem. 2017, 8, 52-73. [CrossRef]

15. Gohy, J.F.; Zhao, Y. Photo-responsive block copolymer micelles: Design and behavior. Chem. Soc. Rev. 2013, 42, 7117-7129. [CrossRef] [PubMed]

16. Govan, J.M.; Young, D.D.; Lively, M.O.; Deiters, A. Optically trigged immune response through photocaged oligonucleotides. Tetrahedron Lett. 2015, 56, 3639-3642. [CrossRef] [PubMed]

17. Takamori, S.; Yamaguchi, S.; Ohashi, N.; Nagamune, T. Sterically bulky caging for light-inducible protein activation. Chem. Commun. (Camb.) 2013, 49, 3013-3015. [CrossRef] [PubMed]

18. Edler, M.; Mayrbrugger, S.; Fian, A.; Trimmel, G.; Radl, S.; Kern, W.; Griesser, T. Wavelength selective refractive index modulation in a ROMP derived polymer bearing phenyl- and ortho-nitrobenzyl ester groups. J. Mater. Chem. C 2013, 1, 3931. [CrossRef]

19. Ryan, D.; Parviz, B.A.; Linder, V.; Semetey, V.; Sia, S.K.; Su, J.; Mrksich, M.; Whitesides, G.M. Patterning multiple aligned self-assembled monolayers using light. Langmuir 2004, 20, 9080-9088. [CrossRef] [PubMed]

20. Doh, J.; Irvine, D.J. Photogenerated polyelectrolyte bilayers from an aqueous-processible photoresist for multicomponent protein patterning. J. Am. Chem. Soc. 2004, 126, 9170-9171. [CrossRef] [PubMed] 
21. Choi, O.J.; Chung, M.K.; Ryu, Y.M.; Lee, M.H. Synthesis and characterization of new positive photosensitive polyimide having photocleavable 4, 5-dimethoxy-2-nitrobenzyl (DMNB) groups. Polymer-Korea 2002, 26, 701-709.

22. Taylor, P.G.; Lee, J.K.; Zakhidov, A.A.; Chatzichristidi, M.; Fong, H.H.; DeFranco, J.A.; Malliaras, G.G.; Ober, C.K. Orthogonal Patterning of PEDOT: PSS for Organic Electronics using Hydrofluoroether Solvents. Adv. Mater. 2009, 21, 2314-2317. [CrossRef]

23. Marchl, M.; Edler, M.; Haase, A.; Fian, A.; Trimmel, G.; Griesser, T.; Stadlober, B.; Zojer, E. Tuning the threshold voltage in organic thin-film transistors by local channel doping using photoreactive interfacial layers. Adv. Mater. Weinheim 2010, 22, 5361-5365. [CrossRef] [PubMed]

24. Willson, C.G. Approaches to the Design of Radiation-Sensitive Polymeric Imaging Systems with Improved Sensitivity and Resolution. J. Electrochem. Soc. 1986, 133, 181. [CrossRef]

25. Wilkins, C.W. Lithographic Evaluation of an o-Nitrobenzyl Ester Based Deep U.V. Resist System. J. Electrochem. Soc. 1982, 129, 2552. [CrossRef]

26. Kim, M.; Choi, J.C.; Jung, H.R.; Katz, J.S.; Kim, M.G.; Doh, J. Addressable micropatterning of multiple proteins and cells by microscope projection photolithography based on a protein friendly photoresist. Langmuir 2010, 26, 12112-12118. [CrossRef] [PubMed]

27. Li, L.; Deng, X.X.; Li, Z.L.; Du, F.S.; Li, Z.C. Multifunctional Photodegradable Polymers for Reactive Micropatterns. Macromolecules 2014, 47, 4660-4667. [CrossRef]

28. Radl, S.; Kreimer, M.; Manhart, J.; Griesser, T.; Moser, A.; Pinter, G.; Kalinka, G.; Kern, W.; Schlögl, S. Photocleavable epoxy based materials. Polymer 2015, 69, 159-168. [CrossRef]

29. Radl, S.; Roppolo, I.; Pölzl, K.; Ast, M.; Spreitz, J.; Griesser, T.; Kern, W.; Schlögl, S.; Sangermano, M. Light triggered formation of photo-responsive epoxy based networks. Polymer 2017, 109, 349-357. [CrossRef]

30. Oliver, W.C.; Pharr, G.M. An improved technique for determining hardness and elastic modulus using load and displacement sensing indentation experiments. J. Mater. Res. 1992, 7, 1564-1583. [CrossRef]

31. Gerbase, A.E.; Petzhold, C.L.; Costa, A.P.O. Dynamic mechanical and thermal behavior of epoxy resins based on soybean oil. J. Am. Oil Chem. Soc. 2002, 79,797-802. [CrossRef]

32. Hosseini Nejad, E.; van Melis, C.G.W.; Vermeer, T.J.; Koning, C.E.; Duchateau, R. Alternating Ring-Opening Polymerization of Cyclohexene Oxide and Anhydrides: Effect of Catalyst, Cocatalyst, and Anhydride Structure. Macromolecules 2012, 45, 1770-1776. [CrossRef]

33. Liu, D.F.; Zhu, L.Q.; Wu, J.; Wu, L.Y.; Lü, X.Q. Ring-opening copolymerization of epoxides and anhydrides using manganese(iii) asymmetrical Schiff base complexes as catalysts. RSC Adv. 2015, 5, 3854-3859. [CrossRef]

34. Pan, X.; Webster, D.C. Impact of structure and functionality of core polyol in highly functional biobased epoxy resins. Macromol. Rapid Commun. 2011, 32, 1324-1330. [CrossRef] [PubMed]

35. Pelliccioli, A.P.; Wirz, J. Photoremovable protecting groups: Reaction mechanisms and applications. Photochem. Photobiol. Sci. 2002, 1, 441-458. [CrossRef] [PubMed]

36. Radl, S.V.; Schipfer, C.; Kaiser, S.; Moser, A.; Kaynak, B.; Kern, W.; Schlögl, S. Photo-responsive thiol-ene networks for the design of switchable polymer patterns. Polym. Chem. 2017, 8, 1562-1572. [CrossRef]

37. Romano, A.; Roppolo, I.; Giebler, M.; Dietliker, K.; Možina, Š.; Šket, P.; Mühlbacher, I.; Schlögl, S.; Sangermano, M. Stimuli-responsive thiol-epoxy networks with photo-switchable bulk and surface properties. RSC Adv. 2018, 8, 41904-41914. [CrossRef]

38. Giebler, M.; Radl, S.V.; Ast, M.; Kaiser, S.; Griesser, T.; Kern, W.; Schlögl, S. Dual-Responsive Polydimethylsiloxane Networks. J. Polym. Sci. Part A Polym. Chem. 2018, 56, 2319-2329. [CrossRef]

39. Rossegger, E.; Hennen, D.; Griesser, T.; Roppolo, I.; Schlögl, S. Directed motion of water droplets on multi-gradient photopolymer surfaces. Polym. Chem. 2019, 10, 1882-1893. [CrossRef]

40. Völklein, F.; Zetterer, T. Praxiswissen Mikrosystemtechnik: Grundlagen-Technologien-Anwendungen; 2., vollständig überarbeitete und erweiterte Auflage; Springer Vieweg: Braunschweig, Germany, 2006; ISBN 9783834891051. 